\title{
Airborne bacterial dispersal during and after dressing and bed changes on burns patients
}

Sarah E Bache*: Burns Research Fellow and Plastic Surgery trainee, Burns Unit, Canniesburn Plastic Surgery Unit, Glasgow Royal Infirmary, Glasgow G4 OSF. sarahbache@doctors.org.uk.

Michelle Maclean: Research Fellow, The Robertson Trust Laboratory for Electronic Sterilisation Technologies (ROLEST), Department of Electronic and Electrical Engineering, University of Strathclyde, Glasgow, UK.

George Gettinby: Professor of Statistics, Department of Mathematics and Statistics, University of Strathclyde, Glasgow, UK.

John G Anderson: Emeritus Professor of Microbiology, The Robertson Trust Laboratory for Electronic Sterilisation Technologies (ROLEST), Department of Electronic and Electrical Engineering, University of Strathclyde, Glasgow, UK.

Scott J MacGregor: Dean of Engineering, The Robertson Trust Laboratory for Electronic Sterilisation Technologies (ROLEST), Department of Electronic and Electrical Engineering, University of Strathclyde, Glasgow, UK.

Ian Taggart: Consultant in Burns and Plastic Surgery, Burns Unit, Canniesburn Plastic Surgery Unit, Glasgow Royal Infirmary, Glasgow, UK.

Department to which this work should be attributed:

Burns Unit, Canniesburn Plastic Surgery Unit, Glasgow Royal Infirmary, 84-106 Castle Street, Glasgow G4 0SF, United Kingdom.

*Denotes corresponding author 


\begin{abstract}
Background: It is acknowledged that activities such as dressing changes and bed sheet changes are high-risk events; creating surges in levels of airborne bacteria. Burns patients are particularly high dispersers of pathogens; due to their large, often contaminated, wound areas. Prevention of nosocomial cross-contamination is therefore one of the major challenges faced by the burns team. In order to assess the contribution of airborne spread of bacteria, air samples were taken repeatedly throughout and following these events, to quantify levels of airborne bacteria.
\end{abstract}

Methods: Air samples were taken at three minute intervals before, during and after a dressing and bed change on a burns patient using a sieve impaction method. Following incubation, bacterial colonies were enumerated to calculate bacterial colony forming units per $\mathrm{m}^{3}$ $\left(\mathrm{cfu} / \mathrm{m}^{3}\right)$ at each time point. Statistical analysis was performed, whereby the period before the high-risk event took place acted as a control period. The periods during and after the dressing and bed sheet changes were examined for significant differences in airborne bacterial levels relative to the control period. The study was carried out four times, on three patients with burns between $35 \%$ total burn surface area (TBSA) and 51\% TBSA.

Results: There were significant increases in airborne bacteria levels, regardless of whether the dressing change or bed sheet change took place first. Of particular note, is the finding that significantly high levels (up to $2614 \mathrm{cfu} / \mathrm{m}^{3}$ ) of airborne bacteria were shown to persist for up to approximately one hour after these activities ended.

Discussion: This is the most accurate picture to date of the rapidly changing levels of airborne bacteria within the room of a burns patient undergoing a dressing change and bed change. The novel demonstration of a significant increase in the airborne bacterial load during these events has implications for infection control on burns units. Furthermore, as these increased levels remained for approximately one hour afterwards, persons entering the room both during and after such events may act as vectors of transmission of infection. It is suggested that appropriate personal protective equipment should be worn by anyone entering the room, and that rooms should be quarantined for a period of time following these events.

Conclusion: Airborne bacteria significantly increase during dressing and sheet changes on moderate size burns, and remain elevated for up to an hour following their cessation. 


\section{Introduction}

The primary modes of cross-contamination of pathogens between burns patients are believed to be direct and indirect contact either from the hospital environment and equipment, or via staff [1]: The contribution of the airborne route is less well defined. When a burns patient is at rest in bed, the dispersal of bacteria from their wounds is likely to be negligible. On the instigation of activity however, a proliferation of bacteria are released into the air, and onto surrounding surfaces, after travelling a distance of up to two metres from whence they came [2]. Certain events have been identified as high-risk periods of bacterial liberation. Bed sheet changes are one such event creating enhanced bacterial dispersion. Mean counts of airborne methicillin resistant Staphylococcus aureus (MRSA) from infected patients have been shown to be 4.7 colony forming units per $\mathrm{m}^{3}\left(\mathrm{cfu} / \mathrm{m}^{3}\right)$ during rest periods, rising to $116 \mathrm{cfu} / \mathrm{m}^{3}$ during bed sheet changes. Levels were shown to remain elevated for at least 15 min after activities ceased [3]. Dressing changes are a further event shown to liberate bacteria from even small non-burn wounds [4].

The contribution of the airborne route can be difficult to quantify, as "it is a characteristic of the airborne route...that whenever there is the possibility of aerial transfer there is almost always the possibility of transfer by other routes." [5] A true airborne route is one in which particles remain suspended in the air almost indefinitely as they are so small, and are transmitted over long distances. Bacteria may be dispersed as clusters without associated cells or liquid, or carried on skin cells, mucus or saliva, which evaporate leaving smaller, more truly airborne, droplet nuclei [6].

Of particular relevance to burns patients are studies of the airborne spread of staphylococci. Samples taken within burns units using settle plates (agar plates exposed within the room for passive collection of airborne microorganisms) demonstrated that burns patients generate high levels of infectious $S$. aureus aerosols [7]. Epidemics of $S$. aureus on burns units have been linked to individual heavy dispersers and a consequential increase in positive air samples [8].

Evidence for airborne bacteria settling and contaminating surrounding surfaces includes a study of sterile operating trays, open but untouched in an operating theatre. Within $4 \mathrm{~h}, 30 \%$ of trays were contaminated, with $44 \%$ of isolates being coagulase negative staphylococci [9]. 
Further work has demonstrated positive air and environmental surface contamination in the vicinity of patients and staff who are carriers of MRSA, indicating an airborne route of dispersal $[10,11]$. One study showed that $33 \%$ of air samples taken in the vicinity of medical and surgical patient carriers of MRSA were positive for the pathogen [10]. The airborne route has previously been attributed to $98 \%$ of bacteria found in wounds during clean operations: approximately $30 \%$ of these being directly precipitated from the air, with the majority being transferred indirectly via the environment or staff [11]. Further reports exist of healthy S. aureus dispersers causing wound infections in nearby patients [12,13]. However, studies comparing the relative contributions to airborne bacteria made by both nasal carriers and patients with wounds colonised with staphylococci have emphasised the importance of friction on the skin and agitation caused by bed making $[5,14]$.

Near ubiquitous colonization of burns wounds means that burns patients may be expected to release higher levels of airborne bacteria than non-burns patients. In the 1970s, one study attempted to link the size of a burn and the airborne dispersal of $S$. aureus during a dressing change: a correlation was demonstrated between the size of the burn and the number of bacteria precipitated onto settle plates over a period of days [7]. More recently, the aerosolisation of MRSA has been demonstrated during 32\% (11/35) of dressing changes on MRSA positive burns patients using a laminar flow air sampler [15].

These two papers begin to tackle the issue of airborne dispersal of bacteria during dressing changes, however they have significant limitations. Settle plates left exposed for several days have the potential to collect bacteria from a plethora of sources. Furthermore their use is limited due to the agar in the settle plates drying out when uncovered for prolonged periods [7]. An air sampler is therefore a preferred sampling tool. However, the authors of the paper using the laminar flow air sampler did not report the point at which sampling was started, nor how long after the dressing change was complete that post-dressing change samples were taken [15]. The experimental methods described below were therefore developed to more accurately evaluate the airborne bacterial dispersal during dressing and bed changes. 


\section{Materials and methods}

\section{Sampling methods and rationale}

A sieve impaction method was chosen for collection of air samples, using a Surface Air System (SAS) Super 180 air sampler (Cherwell Laboratories Ltd., Bicester, UK). Air is aspirated at a fixed velocity for a variable time through a perforated cover. Particles from the air are impacted onto the surface of $90 \mathrm{~mm}$ tryptone soya agar (TSA) plate for recovery: a non-selective, nutrient rich medium. The SAS Super 180 air sampler can sample the air for a variable amount of time, thus sampling variable volumes, but with relatively short sampling times, enabling multiple samples to be taken within a short time frame. Furthermore, it has a rechargeable battery and is small and portable enough to be used in an inpatient isolation room. It was easily cleaned between studies using detergent wipes. It is an established method for measuring air contamination. In contrast, the Anderson air sampler, which separates particles according to size, was found during preliminary work to be too large and cumbersome for sampling within this particular clinical environment, where space is limited. The settle plate method employed by some authors would not allow for the short time intervals required for this study.

All studies took place in inpatient isolation rooms, either on the burns unit or in the intensive care unit, at Glasgow Royal Infirmary. All air entering the rooms in the unit passes through High Efficiency Particulate Absorbing (HEPA) filters, with the rooms kept at negative pressure and the doors closed throughout each study. Air sampling took place in the rooms of four consecutive patients who met the inclusion criteria during the study period. Inclusion criteria were: rooms containing patients with moderate or large sized burns (>30\%TBSA); rooms containing a single patient whom had been nursed in that room for at least 48 hours; and rooms containing patients who were undergoing a full dressing change and sheet change. These patients were included in the study as they would be expected to show high levels of contamination, and dressing changes would take at least 30 minutes - enough time to establish a pattern of events. The only exclusion criteria were rooms containing patients whom had been recently moved or had burns $<30 \%$ TBSA. No additional dressing or bed sheet changes were performed, and no children were included as they are cared for in a separate hospital. Data including age of burn, recent routine wound swab results, time taken for the dressing and bed change to take place and the \%TBSA burn were recorded for each patient. Patients were treated according to standard practice on our burns unit. We aim for 
early excision and split thickness skin autograft or coverage with a dermal substitute in all deep dermal and full thickness burns. Patients with superficial burns, or those deemed too sick for surgical intervention are managed conservatively with dressings and topical agents.

Dressing changes in these patients took place on their bed in their isolation room and would also incorporate a bed sheet change while rolling the patient to apply bandages. Following the dressing and bed change a second, post event, minimal activity period was observed to collect bacteria in the period following. Samples of 500L were taken every $3 \min (2 \mathrm{~min} 47$ sec for aspiration, and $13 \mathrm{sec}$ to change the agar plate). The air sampler was positioned at the foot of the patient bed, and the sampler (SEB) noted the activity taking place at the start of each sampling period. A minimum of 12 samples ( $36 \mathrm{~min}$ ) was taken before the dressing/bed change took place in order to establish the control period. Following collection, at least 8 samples (24 min) were taken. Both the before and after event minimal activity periods varied in length depending on when the staff began the dressing change and what events took place after the dressing and bed change, as no gaps were allowed between 3 min samples, and minimum disturbance to the usual routine of the patients and staff was essential. The intention was to mimic real-life situations as much as possible and not to inconvenience the patient or staff during what can be a distressing and uncomfortable time.

The events examined were divided into three broad activity categories.

Minimal activity ('min'): these took place both before and after the dressing and bed sheet changes and included the patient eating, talking, reading, watching television etc. Nursing input was minimal, such as feeding, measuring observations, attending drips, giving medications, brushing teeth and washing the patient with a damp cloth. This category excluded any bed sheet disturbance or changing and the removal or application of dressings.

- Bed sheet activity ('sheet'): included shaking out or rearranging the bed sheets and blankets, removing soiled laundry, replacing with clean laundry and making the bed.

- Dressing change activity ('dress'): included removing dressings, cleaning wounds and reapplying fresh dressings and splints. 


\section{Incubation and enumeration of air samples}

Following sampling, the TSA plate was removed from the sampler head, and incubated at $37{ }^{\circ} \mathrm{C}$ for $24 \mathrm{~h}$. The bacterial cfu were then enumerated. The raw total number of bacterial cfu counted on the surface of the agar plate was then corrected for the statistical probability of multiple particles passing through the same hole, by referring to correction tables supplied with the equipment. The probable count $(\operatorname{Pr})$ was then used to calculate the cfu per cubic metre of air sampled using the equation:

$$
X=\frac{\operatorname{Pr} x 1000}{V}
$$

Where: $\quad \mathrm{V}=$ volume of air sampled $\operatorname{Pr}=$ probable count $\mathrm{X}=\mathrm{cfu}$ per 1000 litres of air $\left(1000\right.$ litres $\left.=1 \mathrm{~m}^{3}\right)$.

\section{Statistical analysis and establishing a control chart}

Microsoft Excel and Minitab Version 16 were used throughout. The data were input into Excel and raw probable cfu $/ \mathrm{m}^{3}$ counts were converted to log-transformed counts $\left(\log _{e}(\mathrm{X}+1)\right)$. The data were inserted into Minitab. Control charts (I charts) were produced based on both the raw and log-transformed probable $\mathrm{cfu} / \mathrm{m}^{3}$ counts. While raw counts are more readily interpreted by clinicians, log-transformed statistical analysis is generally considered to be superior for analysis of bacterial counts, and both are therefore included here. Mean and standard deviation were estimated by analysing samples from the first period of minimal activity (usually the first 12-18 samples). Once these were calculated, they were applied to the subsequent data. Four internationally accepted tests were applied to the chart. Results that failed to pass any of these tests were indicated in red with a number to denote the statistical test failed, such that the probability of obtaining a false special cause is circa 1 in 100 [16]. The tests that were indicative of a special cause were:

1. One point greater than three standard deviations from centre line

2. Nine points in a row on the same side of the centre line

3. Six points in a row all increasing or decreasing 
4. 14 points in a row, all alternating up or down

Initial analysis was carried out on raw data to create clinically relevant charts. However, the tests were repeated on log-transformed data, as the widely accepted method of analysing bacterial cfu counts.

\section{Results}

\section{Control Charts 1: Patient A with $35 \%$ TBSA burns}

Patient A was a 55 year old with a four day old $35 \%$ TBSA superficial partial thickness flame burn to both upper limbs and lower limbs and chest. The burn had not been surgically debrided as it was mainly superficial, but had been treated with topical silver sulfadiazine. Wound swabs had isolated MRSA. The patient was sedated and mechanically ventilated, with an inhalation injury.

Control charts are shown in Figure 1. Analysis of the raw data shows that the first minimal activity stage has a mean of $121 \mathrm{cfu} / \mathrm{m}^{3}$ and standard deviation of $44.66 \mathrm{cfu} / \mathrm{m}^{3}$ : a mean of $4.63 \log _{c f u / m 3+1}$ and standard deviation of $0.39 \log _{c f u / m 3+1}$ on log-transformed data. At the beginning of the dressing change (which lasted for $51 \mathrm{~min}$ ), the data points are immediately flagged as failing Test 1 (values are > 3 SD above the centre). This is sustained for the first six readings during the dressing change activity: a period of $18 \mathrm{~min}$. The chart appears to return to the control mean, only to go 'out of control' again during the sheet change activity. Levels of airborne bacteria remain 'out of control' for the duration of the second minimal activity period (24 $\mathrm{min})$.

In conclusion, the dressing change on a patient with $35 \%$ TBSA burns created significantly increased levels of airborne bacteria. The bed sheet change also increased airborne bacterial levels, with prolonged high levels following the termination of this activity suggesting that the effects of a sheet change may continue for at least $24 \mathrm{~min}$. This raises the possibility that protective clothing may be needed by anyone entering the room for a period of time during and after a dressing/bed change. 

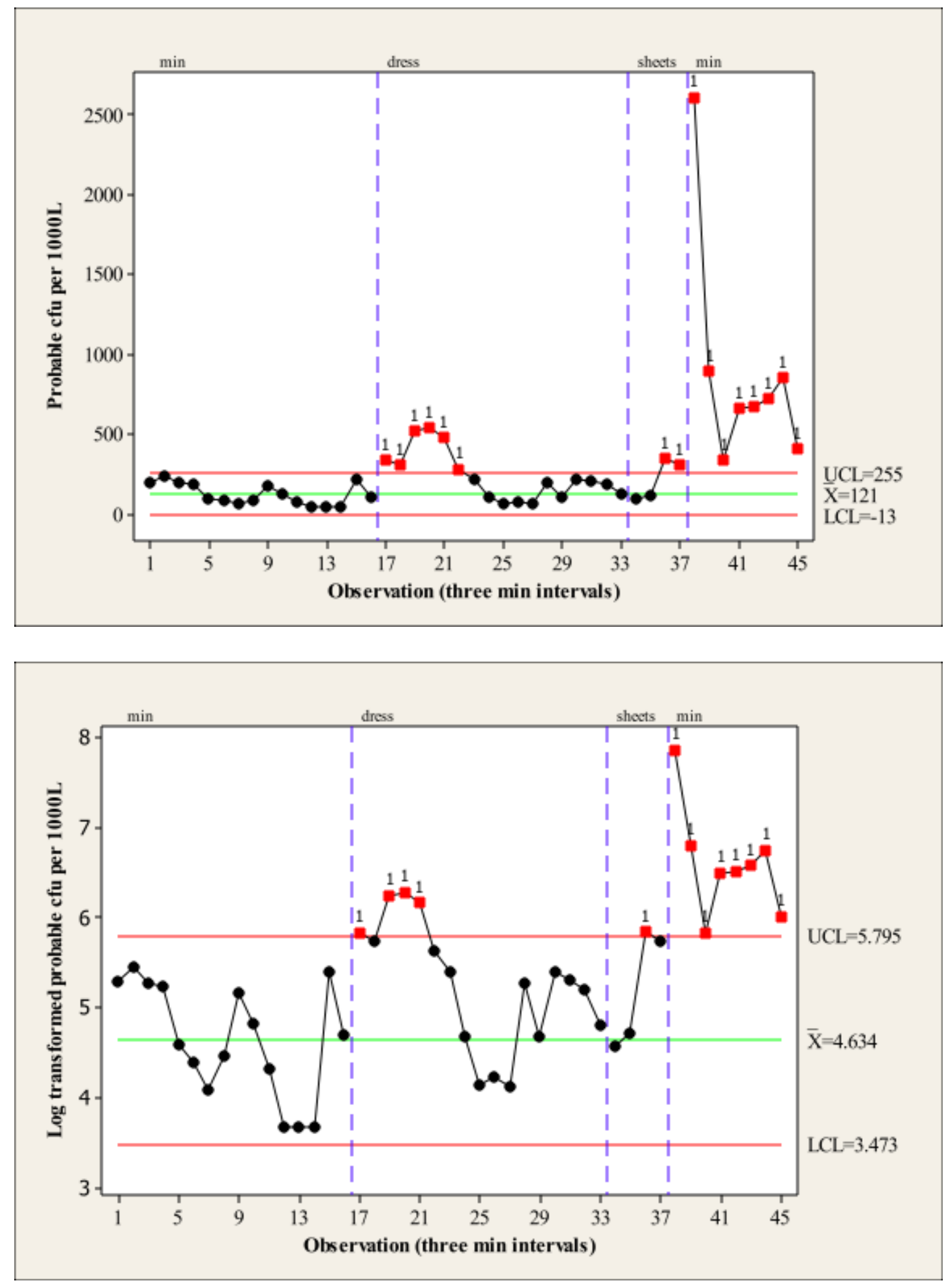

Figure 1: Control Charts 1 (Minitab v16) based on raw data (above) and log-transformed data (below), demonstrating levels of airborne bacteria during events involving Patient A with $35 \%$ TBSA burns. Probable cfu per 1000 L (i.e. $c f u / m^{3}$ ) from air samples taken at 3 min intervals are given. The event has been divided into stages according to the activities taking place (min = minimal activity; dress $=$ dressing change; sheet $=$ bed sheet change). 'Out of control' data points are flagged in red . 
Patient B was a 43 year old with a two day old $45 \%$ TBSA deep partial and full thickness flame burn to both upper limbs and lower limbs, chest, back, face and neck. Part of the burn, amounting to $19 \%$ TBSA had been surgically debrided the day before, with $1 \%$ TBSA covered with skin grafts and $18 \%$ TBSA covered with Integra. No wound swabs had isolated organisms at this point. The patient was sedated and mechanically ventilated, with an inhalation injury.

Control charts are given in Figure 2. Analysis of the raw data shows that the first minimal activity stage has a mean of $21.5 \mathrm{cfu} / \mathrm{m}^{3}$ and standard deviation of $11.86 \mathrm{cfu} / \mathrm{m}^{3}$ : a mean of $2.94 \log _{c f u / m 3+1}$ and standard deviation of $0.56 \log _{c f u / m 3+1}$ for log-transformed data. At the beginning of the dressing change (which lasted for $72 \mathrm{~min}$ ), the data points are immediately flagged as failing Test 1 (values are $>3 \mathrm{SD}$ above the centre). An 'out of control' status is sustained almost continuously throughout the dressing change, sheet change, and for at least 54 min following the event, due to failing Test 2 (more than nine values in a row the same side of the centre line).

This provides evidence that levels of airborne bacteria are significantly increased during a dressing/bed change of a patient with a $45 \%$ TBSA burn. Again, prolonged 'out of control' counts after the activity ceases suggests that protective clothing may be needed by anyone entering the room during and for at least 54 min after a dressing/bed change. 

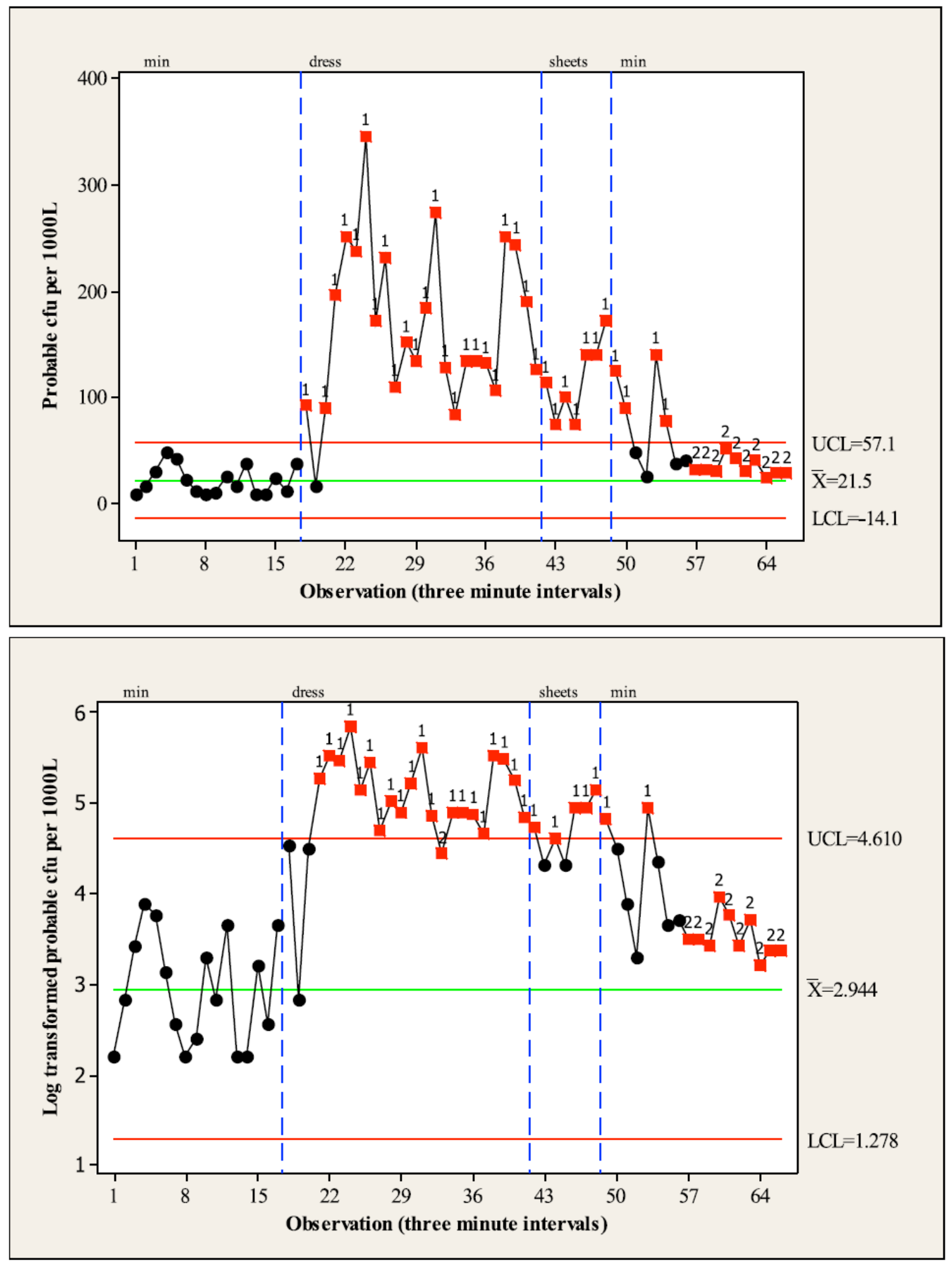

Figure 2: Control Charts 2 (Minitab v16) based on raw data (above) and log-transformed data (below), demonstrating levels of airborne bacteria during events involving Patient B with $45 \%$ TBSA burns. Probable cfu per 1000 L (i.e. cfu $/ \mathrm{m}^{3}$ ) from air samples taken at 3 min intervals are given. The event has been divided into stages according to the activities taking place (min = minimal activity; dress $=$ dressing change; sheet $=$ bed sheet change). 'Out of control' data points are flagged in red. 
Patient $\mathrm{C}$ was a 40 year old with a six day-old $51 \%$ TBSA mixed deep and superficial partial thickness flame burn to both upper limbs and lower limbs, trunk, face and neck. The burn was surgically debrided two days earlier, producing a further $2 \%$ TBSA donor site. Coverage was provided by Integra for $32 \%$ TBSA of the burn to the trunk and upper limbs. Wound swabs had isolated Enterobacter cloacae. The patient was sedated and mechanically ventilated, with an inhalation injury.

Control charts are given in Figure 3. Analysis of the raw data shows that the first minimal activity stage has a mean of $7.0 \mathrm{cfu} / \mathrm{m}^{3}$ and standard deviation of $6.43 \mathrm{cfu} / \mathrm{m}^{3}$ : a mean of $1.785 \log _{c f u / m 3+1}$ and standard deviation of $0.8556 \log _{c f u / m 3+1}$ for log-transformed data. From the beginning of the dressing change (which lasted for $81 \mathrm{~min}$ ), data points are flagged as failing Test 1 (values are > 3 SD above the centre). This is sustained throughout the dressing and sheet change activities. Airborne bacterial counts remain 'out of control' for a minimum of $30 \mathrm{~min}$ after these activities stop.

This study demonstrates significantly increased levels of airborne bacteria during and for at least $30 \mathrm{~min}$ after, a dressing/bed change on a patient with a six day old $51 \%$ TBSA mixed depth burn. 

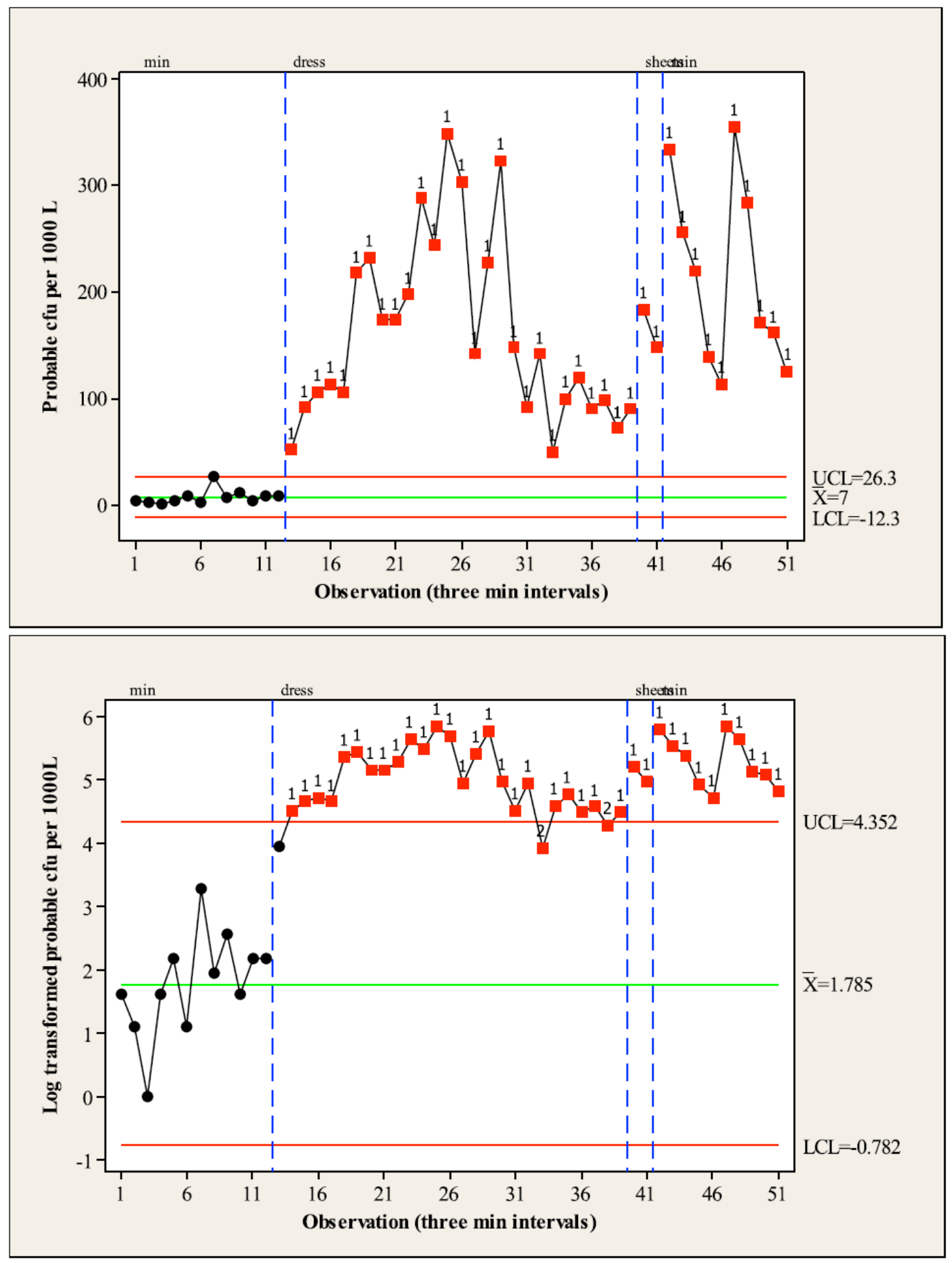

Figure 3: Control Charts 3 (Minitab v16) based on raw data (above) and log-transformed data (below), demonstrating levels of airborne bacteria during events involving Patient $C$ with $51 \%$ TBSA burns at an early point of care. Probable cfu per 1000 L (i.e. $\mathrm{cfu} / \mathrm{m}^{3}$ ) from air samples taken at 3 min intervals are given. The event has been divided into stages according to the activities taking place ( $\min =$ minimal activity; dress = dressing change; sheet $=$ bed sheet change). 'Out of control' data points are flagged in red. 
Patient C was a 40 year old with a 28 day old $51 \%$ TBSA mixed depth (40\%TBSA deep) flame burn to both upper limbs and lower limbs, trunk, face and neck. The burn had been surgically debrided several times by this stage, producing a further $20 \%$ TBSA donor site. Coverage was provided by Integra or skin graft to $32 \% \mathrm{TBSA}$ of the burn to the trunk and upper limbs. Recent wound swabs had isolated P. aeruginosa, MRSA, S. aureus, and coliforms. The patient was alert and breathing spontaneously.

The control chart based on raw data is shown in Figure 4. Analysis of the raw data shows that the first minimal activity stage has a mean of $7.1 \mathrm{cfu} / \mathrm{m}^{3}$ and standard deviation of 5.133 $\mathrm{cfu} / \mathrm{m}^{3}$ : a mean of $1.609 \log _{c f u / m 3+1}$ and standard deviation of $0.926 \log _{c f u / m 3+1}$ for $\log$ transformed data. Of note there were two sheet change activities during this study. This was due to the patient requiring a bedpan, an activity that necessitates in rolling the patient and moving sheets on and off the bed. This is the first time that a sheet change activity has preceded a dressing change activity, and provides evidence that sheet changes in themselves create increases in airborne bacteria. The dressing change (which lasted for $72 \mathrm{~min}$ ), and further sheet change activity produced high levels of airborne bacteria that were also 'out of control' when compared to the first period of minimal activity. For the first time a return to 'control' bacterial levels is achieved, $45 \mathrm{~min}$ after the dressing/bed change activities finish.

This provides evidence that a dressing/bed change carried out on a patient with 28 day old $51 \%$ TBSA mixed depth burns significantly increased airborne bacterial levels, and that the effects of the dressing/bed change remain for a considerable amount of time following their cessation. 


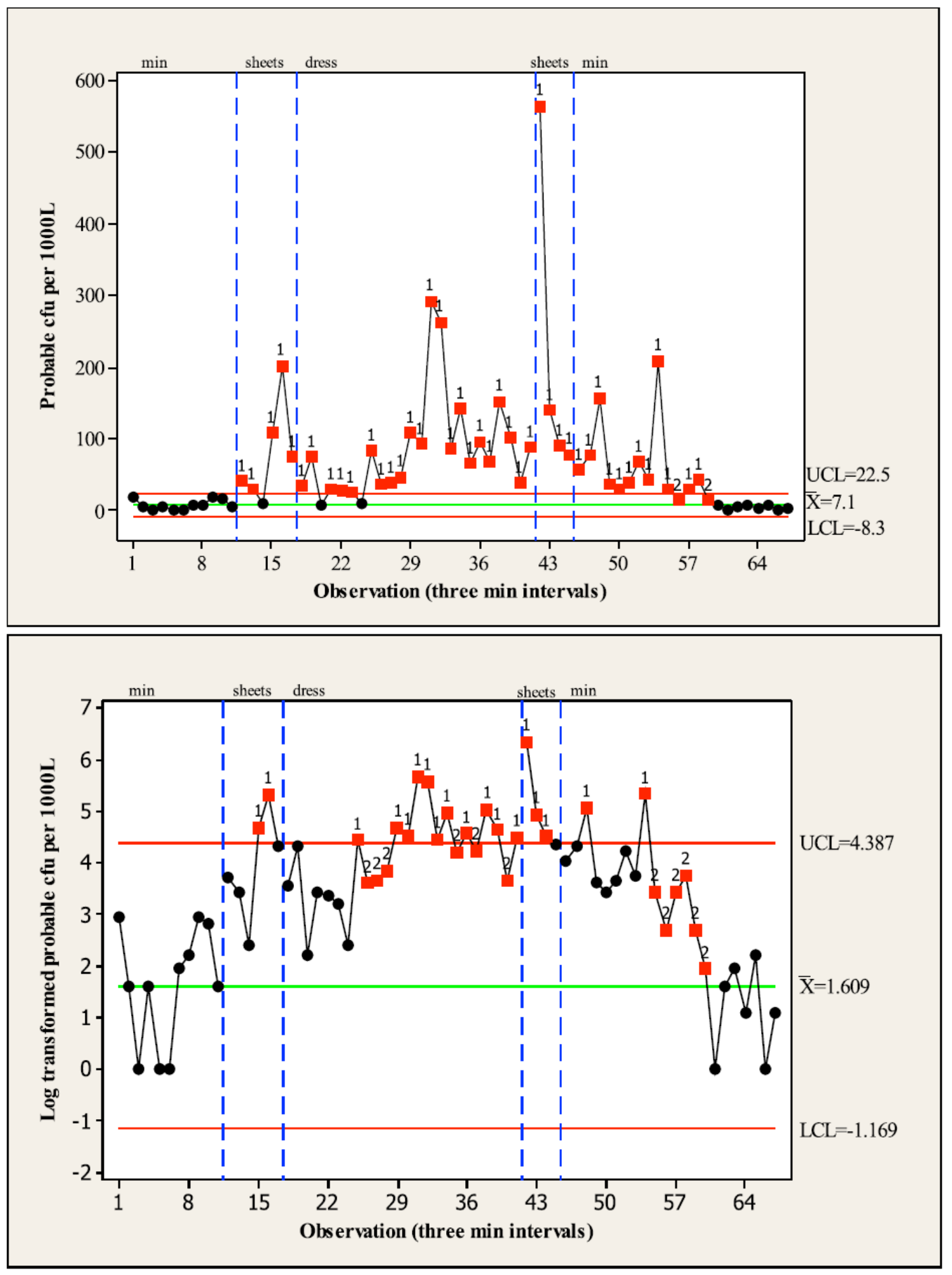

Figure 4: Control Charts 4 (Minitab v16) based on raw data (above) and log-transformed data (below), demonstrating levels of airborne bacteria during events involving Patient C with $51 \%$ TBSA burns at a later stage of care. Probable cfu per $1000 \mathrm{~L}$ (i.e. cfu $/ \mathrm{m}^{3}$ ) from air samples taken at $3 \mathrm{~min}$ intervals are given. The event has been divided into stages according to the activities taking place $($ min $=$ minimal activity; dress $=$ dressing change $;$ sheet $=$ bed sheet change). 'Out of control' data points are flagged in red. 


\section{Discussion}

The four control charts presented demonstrate that the levels of airborne bacteria created during dressing and bed changes are significantly greater than those before the events began. Previous pilot studies had indicated that inter-patient comparisons were not possible due to multiple variables, such as burn size, colonisation of the wound, the amount of movement the patient was capable of, soiling of the bed sheets, and other conditions causing high desquamation levels, such as psoriasis. Therefore, the studies were designed so the patients acted as their own controls. A minimal activity period at the start of each study established 'control' airborne bacterial counts bacteria for that patient in that room at that time in their burn treatment. These baseline levels were seen to significantly increase during dressing and bed sheet changes, regardless of which took place first. Furthermore, the effects lasted for approximately $45 \mathrm{~min}$ to $60 \mathrm{~min}$ after the dressing and bed change ceased. Studies were carried out on patients with burns from $35 \%$ TBSA to $51 \%$ TBSA, and on burns between two and 28 days old.

These control charts are a unique way of quantifying airborne levels of bacteria during activities within a burns unit, and have not been used before in such a setting. Direct comparison with other studies is therefore not possible. Statistical control charts (or Shewhart charts) are one of a number of methods, collectively termed statistical process control (SPC) [17]. SPC was developed originally to improve industrial manufacturing, but more recently it has been applied to the control of standards within healthcare, including infection control [17-19]. As highlighted in the introduction, previous studies used far fewer sampling periods, so an accurate picture of what is taking place during the hour or so it takes to complete a dressing and bed sheet change, and the period beyond, is less apparent $[7,15]$. The control charts here produce an accurate reflection of the level of airborne bacteria throughout the period before, during and after such events, with samples taken every $3 \mathrm{~min}$, and up to 60 samples per study.

These findings implicate the airborne route in the cycle of cross-contamination between burns patients. Evidently, all airborne bacteria will precipitate eventually, onto environmental surfaces, persons present or be inhaled. The precipitation of airborne bacteria has previously been demonstrated in a study of opened sterile operating trays. The instruments inside became contaminated without being touched within an hour, suggesting an airborne route of contamination [9]. Further studies have demonstrated the direct contamination of wounds by 
precipitated airborne bacteria [12]. Combined with the information from the control charts, this implicates the precipitation of airborne bacteria as a means of propagation of nosocomial infection, with significantly increased levels created during dressing and bed sheet changes. Furthermore, the findings suggest that any person entering the room during a dressing change or bed sheet change needs to don adequate personal protective equipment, regardless of whether they are actively participating in the activity or not. It also highlights the risk of contamination, not just of the parts of the body of staff such as the hands and abdomen that come into contact with burns patients and their surroundings, but other areas where airborne bacteria may land (such as the hair). This provides an argument for staff in the room to also wear protective caps and visors. When airborne bacteria ultimately land on surfaces around the room, they will contribute to the reservoir for infection. This highlights the need for a thorough cleaning of the whole room after a dressing and bed change, rather than just areas that have been physically touched by the patient or staff. As the airborne bacterial counts remain significantly raised for a period of up to an hour or more after a dressing change, this cleaning should be delayed until the maximum number of bacteria has precipitated onto surfaces. This may be regarded as a 'high-risk' time, during when anyone entering the room should don adequate personal protective equipment and signage may be used to warn those outside the room.

The importance of bed sheet changing as an independent event leading to airborne dispersal of bacteria has been highlighted, indicating that the same degree of protective clothing may be required for sheet changes as is required for dressing changes. The impact of bed sheet changes on the level of bacteria in the air has previously been demonstrated [3]. However, a relatively low number of samples were taken, three repetitions from six sites each time. The 'post sheet change' sample was only taken once, $60 \mathrm{~min}$ after the end of the bed sheet change. The sampling sites included the soiled sheet itself, which would significantly increase the bacterial counts before the sheet change, and the study did not detail what cleaning took place in the room throughout: vital when sampling surfaces around the room. The authors concluded, however, that the airborne route was a significant means of cross contamination of MRSA between patients via inhalation, direct patient and staff contamination and environmental contamination [3].

Control charts were used as a statistically validated method to demonstrate that the level of contamination significantly increased during a dressing/bed change compared with levels before that event began. It is also useful to consider the levels found in relation to 
recommended guidelines for acceptable levels of airborne contamination. Guidelines state that there should be fewer than $35 \mathrm{cfu} / \mathrm{m}^{3}$ in an empty operating theatre, and fewer than $180 \mathrm{cfu} / \mathrm{m}^{3}$ during an operation [20]. These parameters change to $1 \mathrm{cfu} / \mathrm{m}^{3}$ and $10 \mathrm{cfu} / \mathrm{m}^{3}$ respectively in an'ultra-clean' theatre (usually reserved for patients undergoing joint replacement surgery) [12]. In reality, reported levels of airborne bacteria in operating theatres range from $1-500 \mathrm{cfu} / \mathrm{m}^{3}[12,21]$. Levels in a medical intensive care unit were found to be on average $447 \mathrm{cfu} / \mathrm{m}^{3}$ [22]. One study on a burns unit identified a maximum airborne dispersal of $36 \mathrm{cfu} / \mathrm{m}^{3}$ during a routine nursing period [23]. The same authors found up to 339 airborne S. aureus cfu $/ \mathrm{m}^{3}$ during the early treatment of a burn [7]. A further study on a burns unit identified levels of 1-9 MRSA cfu per $20 \mathrm{~L}$ (50-450 MRSA $\mathrm{cfu} / \mathrm{m}^{3}$ ) [15]. In the four studies presented here, mean levels during minimal activity 'control' periods before the dressing/bed change commenced ranged from $7.0 \mathrm{cfu} / \mathrm{m}^{3}$ to $212.0 \mathrm{cfu} / \mathrm{m}^{3}$ : similar levels to those previously reported. During the dressing/bed changes, the maximum levels recorded for each of the four studies was between $346 \mathrm{cfu} / \mathrm{m}^{3}$ and $2614 \mathrm{cfu} / \mathrm{m}^{3}$ : clearly higher than any of the recommended levels for operating theatres, although no recommendations for burns units exist. This supports the theory that burns patients are potent dispersers of airborne bacteria, particularly during high levels of activity, and that this route is a significant method of crosscontamination on the burns unit [15].

Previous work has claimed a correlation between burn size and amount of bacteria dispersed into the air and onto settle plates [7]. This was not in relation to any particular activity, such as dressing changes, and the settle plates were exposed for varying time periods. Furthermore, the aforementioned paper was from the era of exposed wounds and before the practise of early excision and grafting, so results are not comparable with a modern burns unit. In the more precise measurements outlined here, where air quantity was measured at 3 min intervals, no such correlation could be found between burn size and bacterial dispersal. We believe that this is probably due to the very short time intervals and rapidly changing bacterial levels quantified, and that samples from surfaces within the room would be more likely to demonstrate this correlation. Indeed the size of the burn has been shown to show a highly significant exponential relationship with the level of contamination received by staff undertaking a dressing and bed sheet change, by sampling gowns of the staff members within the room [24].

A limitation of the study was that no attempt was made to perform identification of the bacterial isolates. The number of bacterial cfu that were incubated was so high that we could 
not attempt to identify them all by the identification methods available to us. Nor did we wish to pick out individual colonies to identify, thus introducing a degree of selection bias. Rather, we considered that, given the well documented natural progression of the bioburden of a burn wound, and the pathogenic, or potentially pathogenic, nature of those organisms that were isolated on wound swabs taken from the four patients, the bacteria released into the air during a dressing change on such a wound would be very likely to contain a high proportion of potentially pathogenic isolates. Burns patients are sufficiently immunocompromised that even bacteria that are usually commensal in healthy individuals, such as Staphylococcus epidermidis - a common skin commensal, may prove to be pathogenic. Instead we set out to demonstrate a quantitative increase in airborne bacterial dispersal during a dressing change, relative to during a rest period.

No attempt was made to isolate fungi, as the rate of fungal wound colonization and infection is very low in burns patients $(4.6 \%$ and $2.0 \%$ respectively in one study of 2651 burns patients) [25]. Furthermore, fungi are usually detected at a later stage in the patient treatment (in the same paper at median post burn day 19), and only one patient had burns over six days old. Nevertheless issues associated with fungal infections can be important when dealing with older burn wounds. Aspergillosis (infection by Aspergillus species) of burn wounds usually occurs 2 to 8 weeks after injury [26]. The fungus may sporulate on the wound [27] and it is well known that Aspergillus spores are readily dispersed by air. Since it is considered that Aspergillus infection of the burn wound is largely due to airborne contamination of the burned skin [26] then the issues raised with regard to airborne bacterial dispersal during and after dressing and bed changes on burns patients may well be equally important with regard to the airborne transmission of Aspergillus and perhaps also other fungal pathogens.

Further work may involve the use of an Anderson air sampler, as the first of many other identification techniques, in order to stratify the organisms collected according to their size. This would help determine how long the bacteria are likely to be suspended in the air, as the size of a particle is known to be inversely proportional to the length of time it is airborne [28]. The median particle size dispersed by burns patients has been shown to be between $3.5 \mu \mathrm{m}$ and $5.6 \mu \mathrm{m}$ (indicating an airborne suspension time of between $17 \mathrm{~min}$ and indefinite), thus highlighting the great potential for airborne spread of microorganisms from burns patients [7]. 


\section{Conclusion}

This article has provided evidence of a substantial increase in the levels of airborne bacteria produced in the room of patients with moderate size burns undergoing a dressing and bed sheet change. It has created a detailed picture of the large surges and falls in bacteria suspended in the air that are produced during these events, in three minute intervals: by far the most detailed study of its kind. It raises questions about whether the personal protective equipment worn by staff in the room should be increased. Finally, it highlights the length of time following a dressing and sheet change during which the airborne bacterial levels are still above baseline levels, suggesting a quarantine period may be observed in the room for up to an hour after the event takes place. The airborne route of cross-contamination should not be forgotten in the fight against nosocomial infection on the burns unit, and we hope that these findings have raised awareness of its importance.

\section{References}

1. Gould D. Isolation precautions to prevent the spread of contagious diseases. Nursing Standard 2009; 23(22): 47-55.

2. Walker J T, Hoffman P, Bennett A M, Vos M C, Thomas M, Tomlinson N. Hospital and community acquired infection and the built environment - design and testing of infection control rooms. Journal of Hospital Infection 2007; 65(S2): 43-49.

3. Shiomori T, Miyamoto H, Makishima K, Yoshida et al. Evaluation of bedmaking-related airborne and surface methicillin-resistant Staphylococcus aureus contamination. J Hosp Infect 2002; 50: 30-35.

4. Thom B T, White R G. The dispersal of organisms from minor septic lesions. Journal of Clinical Pathology 1962; 15: 559

5. Williams R E O. Epidemiology of Airborne Staphylococcal Infection. Bacteriological Reviews 1966; 30(3): 660-72.

6. Tang J W, Eames Y L I, Chan P K S, Ridgway G L. Factors involved in the aerosol transmission of infection and control of ventilation in healthcare premises. Journal of Hospital Infection 2006; 64: 100-114 
7. Hambraeus A. Dispersal and transfer of Staphylococcus aureus in an isolation ward for burned patients. J Hyg Camb 1973; 71: 787-797.

8. Khojasteh V J, Edwards-Jones V, Childs C, Foster H A. Prevalence of toxin producing strains of Staphylococus aureus in a paediatric burns unit. Burns 2007; 33: 334-340.

9. Dalstrom D J, Venkatarayappa I, Manternach A L, Palcic M S, Heyse B A, Prayson M J. Time-dependent contamination of opened sterile operating-room trays. The Journal of Bone and Joint Surgery 2008; 90: 1022-5

10. Sexton T, Clarke P, O’Neill E, Dillane T, Humphreys H. Environmental reservoirs of methicillin-resistant Staphylococcus aureus in isolation rooms: correlation with patient isolates and implications for hospital hygiene. Journal of Hospital Infection 2006; 62: 187-94.

11. Walter C W, Kundsin R B, Brubaker M M. The incidence of airborne wound infection during operation. Journal of the American Medical Association 1963; 186(10): 908-913.

12. Whyte W, Hodgeson R, Tinkler J. The importance of airborne bacterial contamination of wounds. Journal of Hospital Infection 1982; 3: 123-135.

13. Tanner EI, Bullin J, Bullin CH, Gamble DR. An outbreak of post-operative sepsis due to a staphylococcal disperser. J Hygiene Camb 1980; 85: 219-25.

14. Clark RP, Calcina-Goff ML. Some aspects of the airborne transmission of infection. J R Soc Interface 2009; 6: S767-82.

15. Dansby W, Purdue G, Hunt J, Arnoldo B, Phillips D et al. Aerolization of methicillin resistant Staphylococcus aureus during an epidemic in a burn intensive care unit. J Burn Care Res 2008; 29: 331-7.

16. Nelson LS. The Shewhart control chart - tests for special causes. J Qual Technol 1984; 16: $237-9$.

17. Thor J, Lundberg J, Ask J, Olsson J, Carli C, Harenstam KP, Brommels M. Application of statistical process control in healthcare improvement: systematic review. Qual Saf Health Care 2007; 16(5): 387-99. 
18. Curran ET, Benneyan JC, Hood J. Controlling methicillin-resistant Staphylococcus aureus: A feedback approach using annotated statistical process control charts. Infect Control Hosp Epidemiol 2002; 18: 2313-18.

19. Norberg A, Christopher NC, Ramundo ML et al. Contamination rates of blood cultures obtained by dedicated phlebotomy vs intravenous catheter. J Americam Med Assoc 2003: 289726-9.

20. Holton J, Ridgeway GL, Reynoldson AJ. A microbiologist's view of commissioning operating theatres. J Hosp Infect 1990; 16: 29-34.

21. Humphreys H, Stacey AR, Taylor EW. Survey of operating theatres in Great Britain and Ireland. J Hosp Infect 1995; 30: 245-52.

22. Bauer TM, Ofner E, Just HM, Just H, Daschner FD. An epidemiological study assessing the relative importance of airborne and direct contact transmission of microorganisms in a medical intensive care unit. J Hosp Infect 1009; 15: 301-9.

23. Hambraeus A. Transfer of Staphylococcus aureus via nurses' uniforms. J Hyg Camb 1973; 71: 799-816.

24. Bache SE, Maclean M, Gettinby G, Anderson JG, MacGregor SJ, Taggart I. Quantifying bacterial transfer from patients to staff during burn dressing and bed changes: Implications for infection control. Burns 2013; 39: 220-8.

25. Horvath EE, Murray CK, Vaughan GM, Chung KK, Hospenthal DR, Wade CE et al. Fungal wound infection (not colonization) Is independently associated with mortality in Burn patients. Ann Surg 2007; 245(6): 978-85.

26. Becker WK, Cioffi WG, McManus AT, Kim SH, McManus WF, Mason AD, et al. Fungal burn wound infection: A 10 year experience. Arch Surg. 1991;126:44-8.

27. Panke TW, McManus AT Jr, McLeod CG Jr. "Fruiting bodies" of aspergillus on the skin of a burned patient. Am J Clin Pathol. 1978 ;69(2):188-9.

28. Knight V. Viruses as agents of airborne contagion. Ann NY Acad Sci 1980; 353: 45-53. 